\title{
Linking Space Observations with Ground Surveys to Better Understand Wisconsin's Conservation Agricultural Landscape
}

\author{
Alana Herro ${ }^{1}$ \\ ${ }^{1}$ Student (Nelson Institute for Environmental Studies, University of Wisconsin-Madison) \\ Madison, WI, USA
}

\begin{abstract}
Cover cropping and no-till or minimum tillage are conservation farming techniques that have numerous benefits for the environment but are not always adopted by farmers because of risks of reduced yield and/or reduced profits. Precise and accurate methods of tracking conservation farming would improve the ability of researchers to maximize benefits and minimize risks. In this paper, satellite data is processed using an expert classification intended to identify cover crops in Wisconsin from the years 2009/2010 to 2018/2019. The results of a survey about farmers' experiences with conservation farming practices is also summarized. The locations of cover cropped farms, identified in the survey, are used to assess the accuracy of the 2018/2019 map produced using the expert classification. The map was found to have an accuracy of only $51 \%$. The survey results found that cover crops and no-till or minimum tillage did not tend to negatively affect yields or profits.
\end{abstract}

\section{Introduction}

Conservation farming practices such as cover cropping and no-till or minimum tillage techniques can have important benefits for the environment (Monast, Sands, \& Grafton, 2018). Growing cover crops refers to the practice of planting a species on a field after the main cash crop has been harvested, when the land would otherwise be fallow, improving soil quality and reducing runoff and soil erosion (Dabney, Delgado, \& Reeves, 2007). No-till or minimum tillage is the practice of not turning the soil, or keeping such activity to a minimum, thereby improving soil health and reducing erosion (Reicosky, 2015). Regardless of the environmental benefits, cover crops are not always economically beneficial to farmers, which can impede adoption (Plastina, Liu, Sawadgo, Miguez, \& Carlson, 2018; Snapp, et al., 2005).

Despite potential economic risks, use of several conservation farming techniques is growing generally across the country (Baranski, et al., 2018). In 2015, Wisconsin had 611,231 acres of cover crops, up 11\% from 2012 (United States Department of Agriculture [USDA], 2017). However, as a percent of Wisconsin's total acreage, the percent of cover cropped fields remains relatively small at just 6\% (Bryant, 2019). Because of the potential of conservation farming techniques to significantly benefit the environment, it is important to find ways to efficiently measure and understand conservation farming trends and impacts. Unfortunately, the USDA Census of Agriculture is only administered once every 5 years and is not published for years after being

\footnotetext{
${ }^{1}$ Funding for this project was provided by the Wisconsin Space Grant Consortium and the American Society for Photogrammetry and Remote Sensing.
} 
administered. Thus, a number of studies have aimed to develop methods for using satellite imagery to detect conservation farming practices and their effects in a timely and effective manner.

For example, a 2009 study in Maryland applied the Normalized Difference Vegetation Index (NDVI) to satellite imagery to determine that planting time significantly impacted cover crop biomass and its associated environmental benefits (Hively, et al., 2009). A 2012 Indiana study found that applying the normalized difference tillage index (NDTI) to multi-temporal Landsat imagery can classify tillage practices with over $90 \%$ accuracy (Zheng, Campbell, \& de Beurs, 2012). And a 2015 Pennsylvania study using Landsat and SPOT satellite data found that over a three-year period, there was a $31 \%$ increase in cover cropping in a study area (Hively, Duiker, McCarty, \& Prabhakara, 2015). Because these satellite data processing techniques do not always work effectively when applied to different geographic locations, there is still a need for researchers to continue to develop, test, and refine new methods of analyzing satellite data for specific regions, including Wisconsin.

Accurate and precise methods of analyzing satellite data can provide important baseline information about agricultural trends. But remote sensing, while being a great resource for mapping the occurrence and the nature of conservation practices on a field-by-field basis across large areas (Hivley, 2009; Hively, 2015; Zheng, 2012) on its own leaves too many unanswered questions about why farmers choose to adopt or not adopt new conservation techniques. Simultaneously, highly detailed plot-level studies have addressed the ecological and soil health benefits of conservation farming (Wortman, Francis, Bernards, Drijbera, \& Lindquist, 2012; DeLaune \& Sij, 2012), but failed to scale up to large regions and become comprehensive.

The goal of this research is to link satellite observations of conservation farming practices with onthe-ground farmer surveys to better understand the ecological, economic, and social benefits of adopting conservation farming in Wisconsin. In this paper, an expert classification developed by Ryan Geygan (in the lab of Dr. Mutlu Ozdogan of the University of Wisconsin-Madison) is applied to satellite imagery of Wisconsin over a 10-year period (November-March from 2009/2010 to 2018/2019) with the intention of identifying cover crops in the state over that same time period. This information is linked to the responses of a survey sent to over 500 Wisconsin farmers in the first half of 2019. The survey contained questions about the farmers' experiences with, and choices behind, cover crop and no-till farming techniques. This paper discusses the process and results of running the expert classification, uses certain survey data to assess the accuracy of the maps developed using the expert classification, and highlights the most significant survey results.

\section{Materials and Methods}

Using an expert classification, satellite data of Wisconsin was analyzed to identify cover crops in the state. Surveys of farmers were administered, and results were analyzed in Excel. Certain data from the surveys was joined to the satellite data.

2.1 Satellite data methods Using an algorithm developed by Ryan Geygan in Dr. Mutlu Ozdogan's lab, tier 1 surface reflectance data from Landsat 5, 7, and 8 satellite imagery (bands 1 
through 5) was compiled via Google Earth Engine (GEE). Spatially, the data was clipped to focus on the state of Wisconsin only. The time period of the data gathered spanned Wisconsin's offpeak growing seasons (November through March) from the years 2009/2010 to 2018/2019.

To analyze the dataset for yearly cover crop extent, NDVI values during the non-growing season were computed for each year. To do this, the NDVI function in GEE was applied to the dataset. For each year, the NDVI values of the relevant months were stacked and then reduced to the 80th percentile. Data from the USDA National Agricultural Statistics Service Cropland Data Layer (CDL) was then applied to the NDVI values: a binary corn/soy mask was applied to identify areas cover crops might exist, and the alfalfa and wheat fields were subtracted, leaving only cover crops to remain on the map.

This process produced 10 maps indicating cover crop values for the years 2009/2010 through 2018/2019, with cover crop pixels represented in black and non-cover crop pixels represented in white. A sieve of 60 was applied to each year's map to reduce noise. QGIS was used to optimize visual presentation of the maps.

2.2 Survey methods In conjunction with the GEE analysis, a survey of 28 questions about cover crop and no-till techniques was distributed to over 500 Wisconsin farmers. The survey was developed with input from agriculture experts from the University of Wisconsin-Madison, community agriculture experts, and farmers. Approximately 50 hard copies of the survey were distributed to farmers in-person at the UW-Extension's Cover Crop Conference on February 20, 2019. Approximately 450 more hard copies of the survey were mailed to farmers included on the Wisconsin Dairy Farmers list obtained from the Department of Agriculture, Trade, and Consumer Protection (DATCP). An electronic version of the survey was distributed through the Wisconsin Crop Manager newsletter (approx. 1,000 members) and its website (approx. 100 views/day), the Family Farm Defenders listserv (approx. 200 farmers on this list), and a small group from Discovery Farms (approx. 12 farmers on this list). There were 94 survey respondents in total. The responses were compiled and analyzed with tables and graphs in Excel.

To conduct an accuracy assessment of the 2018/2019 classified map, the addresses of respondents that chose to provide an address, and whether or not the respondent planted cover crops in the fall of 2018, was noted as in situ data. Then a confusion matrix was compiled. That is, if a farmer indicated that he or she used cover crops in 2018/2019, and the algorithm showed a cover cropped field within $1.7 \mathrm{~km}$ of that address, that point was entered as accurately identified in the confusion matrix. (The average number of acres operated at each of these addresses was 674.7 acres or 2.73 square kilometers. $1.7 \mathrm{~km}$ is the square root of this area, and therefore used as an approximate radius from each address). After eliminating ineligible addresses, 17 addresses of farmers who planted cover crops in 2018, and 18 addresses of people who did not plant cover crops in 2018 were entered into the confusion matrix. 


\section{Key Results}

3.1 Satellite results The satellite data analysis resulted in 10 different black-and-white classified maps, which show the extent of cover crops each year, from 2009/2010 to 2018/2019. A sample of the years are shown below (Fig. 1).
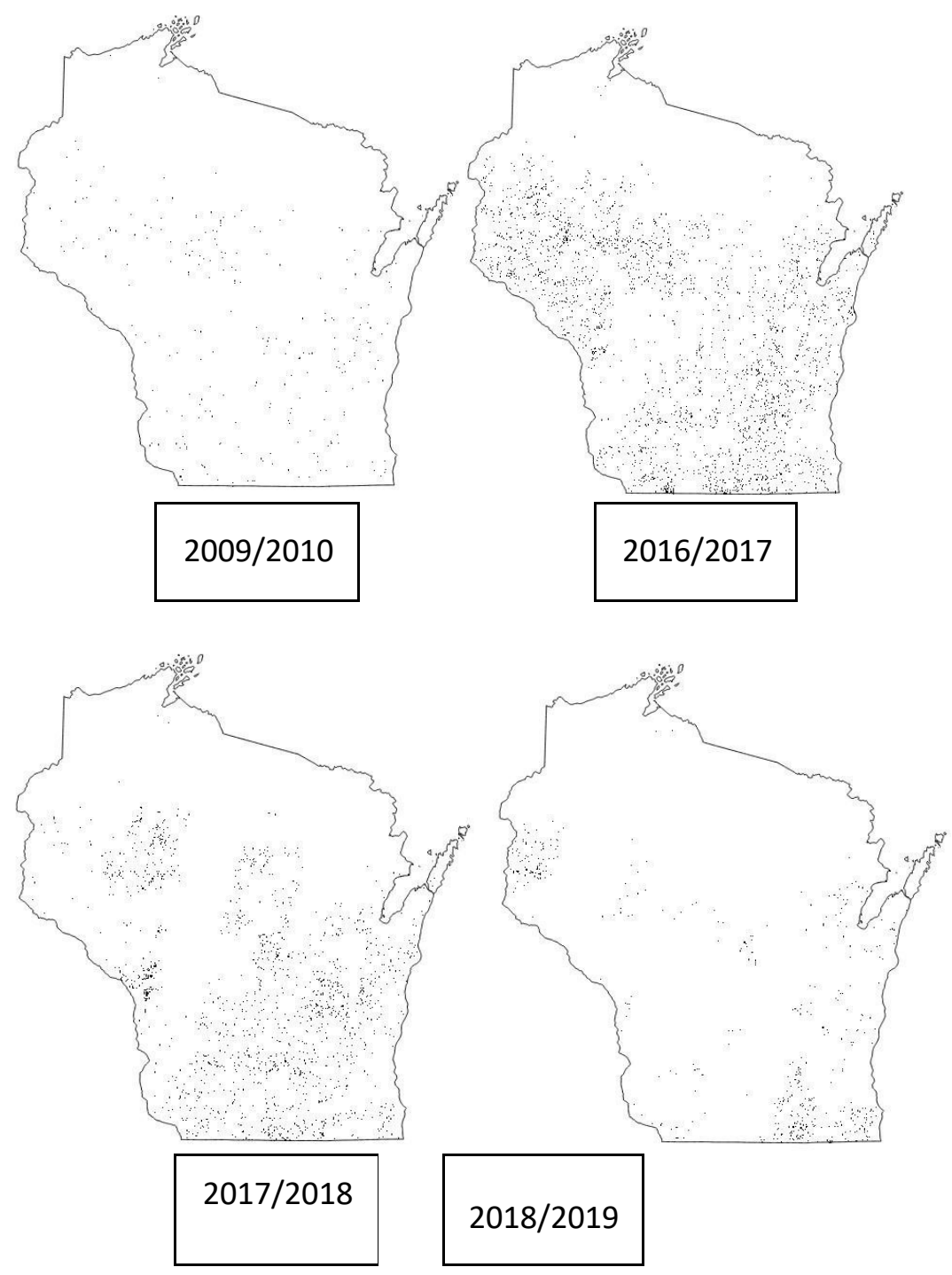

Figure 1: Left to right, top to bottom: maps of Wisconsin from the years 2009/2010, 2016/2017, 2017/2018, and 2018/2019. Black areas indicate where the algorithm identified cover crops. Swaths of white in years 2017/2018 and 2018/2019 indicate probable sensor error. 
The results of the satellite data analysis show a general trend of increasing cover crop area in Wisconsin over the 10-year study period. The first of these maps shows the state of Wisconsin with the extent of cover crops (black) versus non-cover cropped areas (white) from November 2009 through March 2010. Each subsequent map shows the cover crop extent of the same area, with the next year's data from the same months. In this manner, the same general trend of growth of cover crop extent is visualized; by comparing the 2009/2010 classified map to that of 2016/2017, a significant increase of cover cropped area can be seen. The 2017/2018 and 2018/2019 maps show rows or streaks across the map where black areas are diminished or eliminated. These markings are consistent with sensor error.

The overall accuracy of the 2018/2019 classified map (November 2018 through March 2019) was found to be only $51 \%$ according to the confusion matrix developed (Table 1).

\begin{tabular}{|c|c|c|c|c|}
\hline Class & $\begin{array}{l}\text { Cover crop } \\
\text { test }\end{array}$ & $\begin{array}{l}\text { Non cover } \\
\text { crop test }\end{array}$ & Total & $\begin{array}{l}\text { User's } \\
\text { accuracy }\end{array}$ \\
\hline Cover crop & 6.00 & 11.00 & 17.00 & 0.35 \\
\hline $\begin{array}{l}\text { Not cover } \\
\text { crop }\end{array}$ & 6.00 & 12.00 & 18.00 & 0.33 \\
\hline Total & 12.00 & 23.00 & 35.00 & \\
\hline $\begin{array}{l}\text { Producer' } \\
\text { s accuracy }\end{array}$ & 0.50 & 0.48 & $\begin{array}{c}\text { Overall } \\
\text { accurac y }\end{array}$ & 0.51 \\
\hline
\end{tabular}

Table 1: Confusion matrix of the 2018/2019 cover crop map, using survey results as in situ data. Overall accuracy was found to be $51 \%$.

3.2 Survey results With approximately 64,793 farms in Wisconsin (DATCP, 2019), the 94 respondents to the survey led to a confidence level of $95 \%$ with a margin of error of $10 \%$. Respondents operated a total of 60,614 acres of cropland in 2018, or an average of 645 acres per farmer. Of the 94 respondents, 71 indicated they had used cover crops in the last 3 years. Total cover crop acreage surveyed was 21,536 acres, or 303 acres on average per farmer that used cover crops. $66 \%$ percent of the farmers that use cover crops indicated using them for 4 years or more.

Of the cover crop users, $65 \%$ said that cover crops improved their profits. $31 \%$ said cover crops had no impact on profits. Only 5\% said that cover crops decreased their profits. Significantly, $76 \%$ of cover crop users indicated they pay all the costs associated with growing cover crops.

Survey respondents that used cover crops were asked about the yield impact of the conservation farming technique on specific crops: corn for grain, corn for silage, and soybeans. As seen in figure 
2 , most respondents found that regardless of crop, cover cropping either improved yield or had no impact on yield (Fig. 2). Depending on crop type, only $0 \%$ to $10 \%$ found that cover crops decreased yield. Similarly, for the 66 respondents who used no-till or minimum till practices in the previous 3 years, the majority indicated that no-till or minimum till either improved yield or had no impact on yield (Fig. 3). Only 3\% to 5\% found a yield loss due to no-till or minimum till. (For corn for grain, a "minor gain" was a gain of less than 7 bushels per acre. A "significant gain" was more than 7 bushels per acre. For corn for silage, a "minor gain" was a gain of less than 1 ton per acre.

A "significant gain" was more than 1 ton per acre. For soybeans, a "minor gain" was a gain of less than 5 bushels per acre. A "significant gain" was more than 5 bushels per acre.)

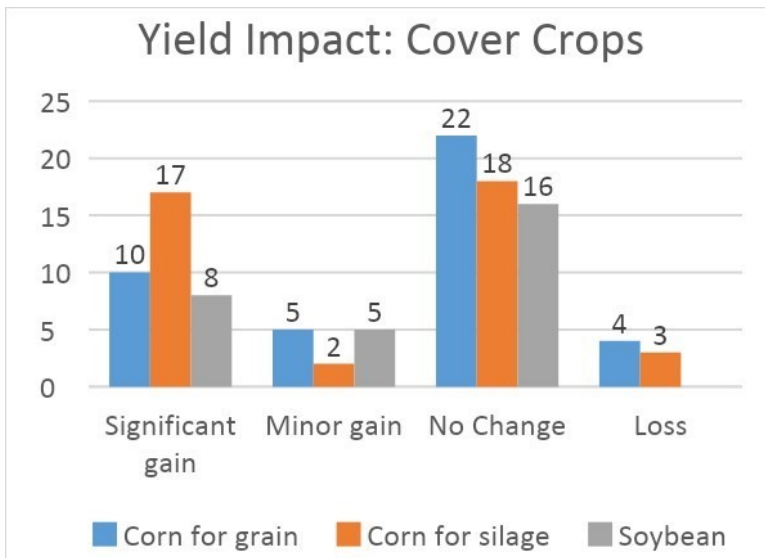

Figure 2: Chart indicating what kind of yield impact cover crops had on respondents' corn for grain, corn for silage, and soybean crops.

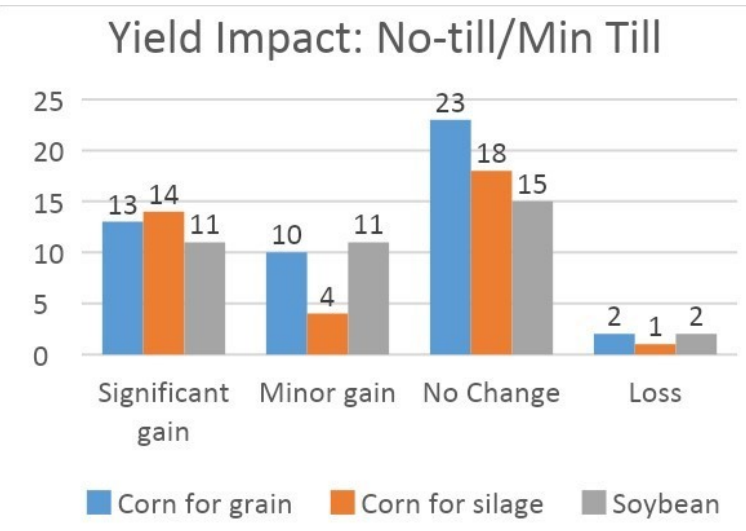

Figure 3: Chart indicating what kind of yield impact no-till/minimum till had on respondents' corn for grain, corn for silage, and soybean crops.

Survey respondents were asked what, before they began using cover crops, was their main reason for choosing to use cover crops. Some of the top answers were "to increase organic matter/improve soil condition/reduce soil compaction (soil health)" (30\%) and "to improve erosion control/improve water quality in my area" (21\%). Only $2 \%$ indicated "to increase yield" and only 
$3 \%$ indicated "to gain weed control benefits" as primary initial factors in their choice to use cover crops. Subjects were subsequently asked to indicate the actual benefits they experienced after using cover crops. While improving soil health (59\%) and reducing erosion/improving water quality $(68 \%)$ were the top answers, $31 \%$ of respondents indicated a yield benefit from using cover crops, and $41 \%$ indicated weed control benefits from the practice (Table 2).

\section{Cover crops}

\begin{tabular}{|l|c|c|}
\hline \multicolumn{1}{|c|}{ Benefit } & $\begin{array}{c}\text { \% Primary } \\
\text { Reason }\end{array}$ & $\begin{array}{c}\text { \% Actual } \\
\text { Experienced } \\
\text { Benefit }\end{array}$ \\
\hline $\begin{array}{l}\text { Erosion/water } \\
\text { quality }\end{array}$ & 21 & 68 \\
\hline Soil health & 30 & 59 \\
\hline Yield & 2 & 31 \\
\hline Weed control & 3 & 41 \\
\hline
\end{tabular}

Table 2: Table illustrates, by percent of responses, primary initial reasons for choosing to begin using cover crops vs. actual experienced benefits of cover crops.

Similarly, for no-till or minimum till, certain reasons for initially choosing to use the technique were more popular than others. Reducing erosion/improving water quality received a response rate of $23 \%$, and $76 \%$ indicated experiencing this benefit. "To reduce input expenses" was indicated as a primary reason $32 \%$ of the time, and $71 \%$ experienced this benefit. However, only $4 \%$ indicated improving yield as a primary reason to use the conservation farming technique, while a full $36 \%$ experienced this benefit. Only 5\% indicated weed control health as a primary initial reason for choosing no-till/minimum till, yet 29\% said they experienced this benefit (Table 3).

\section{No-till or minimum tillage}

\begin{tabular}{|l|c|c|}
\hline \multicolumn{1}{|c|}{ Benefit } & $\begin{array}{c}\text { \% } \\
\text { Primary } \\
\text { Reason }\end{array}$ & $\begin{array}{c}\text { \% Actual } \\
\text { Experienced } \\
\text { Benefit }\end{array}$ \\
\hline $\begin{array}{l}\text { Erosion/water } \\
\text { quality }\end{array}$ & 23 & 76 \\
\hline Input costs & 32 & 71 \\
\hline Yield & 4 & 36 \\
\hline Weed control & 5 & 29 \\
\hline
\end{tabular}


Table 3: Table illustrates, by percent of responses, primary initial reasons for choosing to begin using no-till or minimum tillage vs. actual experienced benefits of no-till or minimum tillage.

The locations of the cover croppers (used in building the confusion matrix) were also put into a table indicating slope, soil type, and cover crop impact on profits for those locations. Most respondents indicated that cover crops either increased profits or had no impact on profits, with only one respondent indicating cover crops decreased profits (Table 4).

\begin{tabular}{|c|c|c|c|c|}
\hline \multirow[t]{2}{*}{$\begin{array}{c}\text { Slope } \\
(\%)\end{array}$} & \multirow[t]{2}{*}{ Soil name } & \multicolumn{3}{|c|}{ Cover crop impact on profits } \\
\hline & & Increase & $\begin{array}{c}\text { No } \\
\text { Impac } \\
t\end{array}$ & $\begin{array}{l}\text { Decreas } \\
\text { e }\end{array}$ \\
\hline 0 to 2 & Ionia silt laom & $x$ & & \\
\hline 0 to 2 & Kewaunee silt loam & $x$ & & \\
\hline 0 to 2 & Pella silt loam & $x$ & & \\
\hline 0 to 3 & Dells silt loam & & $x$ & \\
\hline 0 to 3 & Matherton silt loam & $x$ & & \\
\hline 0 to 3 & Plano silt loam & & $x$ & \\
\hline 0 to 3 & Withee silt loam & $x$ & & \\
\hline 1 to 6 & Loyal silt loam & & $x$ & \\
\hline 1 to 6 & Loyal silt loam & $x$ & & \\
\hline 1 to 6 & Loyal silt loam & $x$ & & \\
\hline 2 to 6 & Kewaunee loam & $x$ & & \\
\hline 2 to 6 & Kidder loam & & $x$ & \\
\hline 2 to 6 & Tama silt loam & $x$ & & \\
\hline 2 to 6 & Valton silt loam & & $x$ & \\
\hline 2 to 6 & Rosholt sandy loam & $x$ & & \\
\hline
\end{tabular}




\begin{tabular}{|l|l|c|c|c|}
\hline $\begin{array}{l}12 \text { to } \\
20\end{array}$ & Urne fine sandy loam & & $\mathrm{X}$ \\
\hline $\begin{array}{l}30 \text { to } \\
60\end{array}$ & $\begin{array}{l}\text { Doreton, very } \\
\text { stonyElbaville } \\
\text { complex }\end{array}$ & $\mathrm{X}$ & & \\
\hline
\end{tabular}

Table 4: Table indicates the soil type and slope on which cover croppers operate, and what impact cover crops had on yield for those conditions.

\section{Discussion}

There are several interesting results from the analysis of the collected data. Regarding the satellite data and expert classification, the 10 maps of cover crops in Wisconsin from 2009/2010 to 2018/2019 indicate a general trend of growth, when years where sensor error is prominent are eliminated (i.e. 2017/2018 and 2018/2019). A trend of growth corresponds with the USDA Census of Agriculture's records of cover crop growth in Wisconsin. However, the low accuracy of the map (51\%) indicates that either the algorithm needs improvement, the method of gathering in situ data needs to be improved, or both. It is also probable that sensor error was a factor in reducing the accuracy of the map. Precise GPS coordinates of cover cropped fields would likely be the best in situ data to reassess the algorithm. As it stands, the expert classification employed for this research is likely best used, at most, as a general visual representation of the status of cover crops in the state.

Regarding the survey data, perhaps the most significant results are the high proportion of farmers that felt cover crops improved their profits $(65 \%)$ or had no impact on profits $(31 \%)$. Other studies have found more mixed results when it comes to the profitability of cover crops. The small margins in farming often preclude farmers from risking new techniques; but a technique that has a low risk of decreasing profits and simultaneously benefits the environment might be more appealing. It should be noted that a large portion of the survey respondents were at a cover crop conference, and so may be farmers who are already inclined to think favorably of cover crops. Another large portion of respondents were dairy farmers. Dairy farms may benefit more from cover crops because they may be located on steeper land, and may use cover crops as feed for livestock, which would reduce the farm's overall costs. It should also be noted that the survey simply asked for farmers' impression of the impact of cover crops on their profits; no verifying data was collected to corroborate these responses.

For organizations hoping to encourage more farmers to use cover crops, the results around primary initial reasons for choosing the conservation farming techniques and the actual benefits realized may be most intriguing. The research suggests that improved yield and weed control may be underrecognized benefits of the conservation farming techniques studied. Focusing promotional materials and messages on these lesser-known benefits could help achieve goals of spreading conservation farming to more farmers. It should be noted that while survey takers were asked to only select one answer for their initial reason for choosing the conservation farming techniques, some selected more than one response. To address this in the data analysis, each survey taker was given 1 "point" that was divided equally among the number of responses they 
chose. Electronic surveys, which can eliminate user error of this kind, would be the preferred method of collecting this kind of data in the future.

The small dataset connecting soil type, slope, and cover crop impact on profits may be useful to farmers who have the same conditions on their land and want to know what impact on profits another farmer has experienced with their same soil type and/or slope.

The preliminary results of this research project were presented to three Wisconsin-based organizations: Clean Lakes Alliance, Rock Lake Improvement Association, and the Cover Crops Research and Outreach Project (CCROP, a collaboration between the Agricultural Research Service Dairy Forage Research Center, UW-Madison's Center for Integrated Agricultural Systems, and the Michael Fields Agricultural Institute). These groups suggested further research that could aid them in their organizational goals, including combining the data with hyperspectral data to better identify cover crop species; asking farmers more specifics about which input costs are lowered with conservation farming techniques; and using the maps to target highest priority areas for cover crops, regionally.

\section{Acknowledgements}

I would like to thank Wisconsin Space Grant Consortium and NASA for funding this research project via the Dr. Laurel Salton Clark Memorial Fellowship; the American Society for Photogrammetry and Remote Sensing for funding the associated transportation costs via the Ta Liang Memorial Award; my advisor Mutlu Ozdogan and colleague Ryan Geygan for allowing me to use the expert classification Mr. Geygan developed in Dr. Ozdogan's lab, as well as invaluable help with the rest of the project; Paul Mitchell, Jeremy Beach and the staff of the UW-Madison Agriculture \& Applied Economics (AAE) department for survey development support, advice, and distribution funding, Stephen Ventura and Matthew Ruark of the UW-Madison Department of Soil Science for survey and research guidance; Kara O'Connor of the Wisconsin Farmers Union, Arlyn Halvorson, Dane County Crops and Soils Educator Heidi Johnson of the UW-Extension, Iowa County's Uplands Watershed Group, UW-Extension's 2019 Cover Crop Conference organizers including John Gaska of the UW-Madison Agronomy department, the Wisconsin Crop Manager newsletter organizers, Family Farm Defenders, Discovery Farms, The Clean Lakes Alliance, Rock Lake Improvement Association, CCROP, and especially all the farmers that helped in the development of the survey and those that took the survey.

\section{References}

Baranski, M., Caswell, H., Claassen, R., Cherry, C., Jaglo, K., Lataille, A.,...Zook, K. (2018). Agricultural Conservation on Working Lands: Trends From 2004 to Present. (Technical Bulletin Number 1950). Washington, D.C.: Office of the Chief Economist, U.S. Department of Agriculture.

Bryant, L. (2019, April 15). Good news about cover crops from the census of agriculture. Retrieved from https://www.nrdc.org/experts/lara-bryant/good-news-about-cover-crops-censusagriculture

Dabney, S.M., Delgado, J.A., \& Reeves, D.W. (2007). Using winter cover crops to improve soil and water quality. Communications in Soil Science and Plant Analysis, 32, 1221-1250. https://doi.org/10.1081/CSS-100104110

DeLaune, P.B. \& Sij, J.W. (2012). Impact of tillage on runoff in long term no-till wheat systems. Soil and Tillage Research, 124, 32-35. https://doi.org/10.1016/j.still.2012.04.009 
Hively, W.D., Duiker, S., McCarty, G., \& Prabhakara, K. (2015). Remote sensing to monitor cover crop adoption in southeastern Pennsylvania. Journal of Soil and Water Conservation, 70, 340-352. https://doi.org/10.2489/jswc.70.6.340

Hively, W.D., Lang, M., McCarty, G., Keppler, J., Sadeghi, A., \& McConnell, L. (2009). Using satellite remote sensing to estimate winter cover crop nutrient uptake efficiency. Journal of Soil and Water Conservation, 64, 303-313. https://doi.org/10.2489/jswc.64.5.303

Monast, M., Sands, L., \& Grafton, A. (2018). Farm finance and conservation [PDF file]. Retrieved from https://www.edf.org/sites/default/files/documents/farm-finance-report.pdf

Plastina, A., Liu, F., Sawadgo, W., Miguez, F., \& Carlson, S. (2018). Annual net returns to cover crops in Iowa. Journal of Applied Farm Economics, 2, article 2. https://docs.lib.purdue.edu/jafe/vol2/iss2/2

Reicosky, D.C. (2015). Conservation tillage is not conservation agriculture. Journal of Soil and Water Conservation, 70, 103A-108A. doi: 10.2489/jswc.70.5.103A

Snapp, S., Swinton, S., Labarta, R., Mutch, D., Black, J., Leep R.,...O'Neil, K. (2005). Evaluating cover crops for benefits, costs and performance within cropping system niches. Agronomy Journal, 97, 322-332. doi:10.2134/agronj2005.0322

United States Department of Agriculture. (2017). Census of Agriculture. Retrieved from https://www.nass.usda.gov/Publications/AgCensus/2017/index.php

$\begin{array}{lllll}\text { Wisconsin } & \text { Agricultural } & \text { Statistics } & \text { (2019). } & \text { Retrieved }\end{array}$ https://datcp.wi.gov/Pages/Publications/WIAgStatistics.aspx

Wortman, S.E., Francis, C.A., Bernards, M.L., Drijbera, R.A., \& Lindquist, J.L. (2012). Optimizing cover crop benefits with diverse mixtures and an alternative termination method. Agronomy Journal, 104, 1425-1435. doi:10.2134/agronj2012.0185

Zheng, B., Campbell, J., \& de Beurs, K. (2012). Remote sensing of crop residue cover using multi- temporal Landsat imagery. Remote Sensing of Environment, 117, 177-183.

https://doi.org/10.1016/j.rse.2011.09.016 